\title{
Visual problems in the elderly population and implications for services
}

\author{
R P L Wormald, L A Wright, P Courtney, B Beaumont, A P Haines
}

\begin{abstract}
Objective-To determine the prevalence of visual disability and common eye disease among elderly people in inner London.
\end{abstract}

Design-Cross sectional random sample survey.

Setting-Inner London health centre.

Subjects-Random sample of people aged 65 and over taken from practice's computerised age-sex register.

Main outcome measures-Presenting binocular Snellen $6 \mathrm{~m}$ distance acuity and best monocular $3 \mathrm{~m}$ Sonksen-Silver acuity to classify prevalence of blindness by World Health Organisation criteria (less than $3 / 60$ in better eye) and American criteria for legal blindness (better eye equal to $6 / 60$ or less) and of low vision by WHO criteria (best acuity 6/18) and visual impairment by American criteria (less than $6 / 12$ or $20 / 40$ but greater than $6 / 60$ or $20 / 200$ in better eye). Principal cause of visual loss by diagnosis, referral indication by cause to hospital eye service, and proportion of cases known to primary care.

Results -207 of $288(72 \%)$ eligible people were examined. $17(8 \%)$ housebound subjects were examined at home. The prevalence of blindness was $1 \%$ by WHO criteria and $3.9 \%$ by American criteria. The prevalence of low vision (WHO criteria) was $\mathbf{7 . 7 \%}$. The prevalence of visual impairment (American criteria) was 10.6\%. Cataract accounted for $75 \%$ of cases of low vision. Only eight out of 16 patients with low vision were known by their general practitioner to have an eye problem. 56 subjects (27\%) would probably have benefited from refraction. Comparisons with studies in the United States and Finland suggested higher rates in this sample, mainly due to the prevalence of disabling cataract.

Conclusion-There seems to be a considerable amount of undetected ocular disease in elderly people in the community.

ECIV 9E

R P L Wormald, lecturer

L A Wright, research assistant

P Courtney, lecturer

London N1 3NG

B Beaumont, general

practitioner

University College and Middlesex School of Medicine, Whittington Hospital, London N19 5NF A P Haines, professor of primary health care

Correspondence to: Mr R Wormald, Academic Unit of Ophthalmology, Western Ophthalmic Hospital, London NW1 SYE. impairment. A community study conducted in Melt Mowbray, Leicestershire, ${ }^{4}$ found high prevalences of common visually disabling conditions in a sample of patients aged 75 and over. The Framingham eye survey $^{5}$ represented mainly middle class white
Americans aged over 55 and is most frequently cited for prevalence estimates of eye disease in industrialised countries.

In London there is a range of facilities available for ophthalmological services but the extent to which the needs of elderly people are being met is not known. The number of elderly people - particularly those aged 75 and over - is expected to increase significantly in the future, which will lead to an increased burden of visual disability and ocular morbidity. ${ }^{6}$

The following survey was undertaken to estimate the prevalence of common eye disorders in an elderly inner city population and to see whether people with visual impairment were known to services.

\section{Subjects and methods}

We present the findings from a $50 \%$ random sample of patients aged 65 and over from a practice with a total population of around 9000. Information on nonattenders in this subsample was available from the practice records.

A total of 288 subjects aged 65 and over were identified from the age-sex register and invited by letter from the general practitioners to participate in a survey of eye health. The survey clinic was established in a day centre for the elderly situated immediately next door to the practice premises. Refusers were asked to give reasons for not wishing to participate.

A brief questionnaire asking for demographic and socioeconomic details as well as relevant medical and ophthalmic history preceded a complete ocular examination. Binocular Snellen $6 \mathrm{~m}$ visual acuity with any spectacles normally worn and uniocular $3 \mathrm{~m}$ SonksenSilver visual acuity (measured with a pin hole when 6/9 equivalent was not achieved), aided by spectacles if usually worn, were taken as the last line read correctly. Near vision was recorded as being able to read N6 with normal reading correction as required. Improvement in distance acuity of greater than one Snellen (equivalent) line with pin hole with one or both eyes was taken as an indication of potential benefit from refraction. Similarly, poor near vision in the presence of good distance acuity was an indication of requirement for new near correction. Therefore, formal refraction was not undertaken but spectacles were assessed for their adequacy.

The central visual field was tested with the Henson CFS2000 in all participants attending the clinic who could perform the test $(81 \%)$. Confrontation fields were used when appropriate for those unable to manage automated testing and on home visits. Intraocular pressure was tested with the Perkins mark 2 applanation tonometer and if raised checked with the Goldmann applanation tonometer with the slit lamp. Pupil size and reactions were recorded, as was the general health of the exterior of the eye. After dilatation with tropicamide $1 \%$ the optic disc vertical cup to disc ratio 
was recorded and the macula and posterior pole examined with a Volk aspheric 90 dioptre lens. Lens opacities were not formally graded but were assessed clinically by one of two ophthalmologists (RW or PC) as significant or otherwise. When indicated the retinal periphery was examined with a binocular indirect ophthalmoscope and 28 dioptre aspheric lens. Patients found to have ophthalmological conditions requiring further assessment or treatment, or both, were referred to a local eye unit (Moorfields Eye Hospital or the Whittington Hospital).

The $95 \%$ confidence intervals around estimates of prevalence were calculated by the exact method for small proportions and the normal approximation to the binomial distribution for larger ones.? Prevalence was calculated on the basis of subjects examined, although some data were available on the prevalence of visual loss among non-respondents from the practice notes.

\section{Results}

There was no significant difference in the proportions of men and women among attenders and nonattenders. A total of 106 attenders (51\%) were aged 75 and over.

\section{PREVALENCE OF BLINDNESS AND VISUAL IMPAIRMENT}

Prevalence estimates are summarised in the table with $95 \%$ confidence intervals stratified by age and sex. There were two blind participants (World Health Organisation criteria), one of whom was registered. Both were over 80 . Another (also over 80 ) was registered blind but had vision better than 3/60 in one eye. Eight subjects fulfilled the American criteria of legal blindness. Low vision by WHO criteria is visual acuity less than $6 / 18$ in either eye: 16 subjects had low vision $(7 \cdot 7 \% ; 95 \%$ confidence interval $4 \cdot 5 \%$ to $12 \cdot 2 \%)$. Visual impairment by American standards is best acuity of less than $6 / 12(20 / 40)$ and better than $6 / 60$, and there were 22 such subjects $(10.6 \% ; 95 \%$ confidence interval $6.9 \%$ to $14 \cdot 8 \%$ ). Eight of the 16 subjects with low vision (less than 6/18) were known by their doctor to have an eye complaint.

Of the 17 subjects who were examined in their homes, seven $(41 \%$; $95 \%$ confidence interval $18.4 \%$ to $67 \cdot 1 \%$ ) had low vision (by WHO criteria). Multiple disabilities were common in this group and in no case was visual impairment the sole cause of being housebound.

Fifty six subjects $(27 \%$; $95 \%$ confidence interval $21 \cdot 0 \%$ to $33 \cdot 1 \%$ ) would probably have benefited from a new refraction. Among these, two (11\%) cases of low vision (WHO criteria) were accounted for by uncorrected refractive error, and 21 (49\%) cases of visual impairment (American criteria) were similarly caused.

\section{NON-RESPONDENTS}

Eighty one people did not participate in the study. Eleven refused saying they had no eye problems or had recently seen an optician. The practice notes of the remaining 70 non-attenders were examined for any comment on vision or attendance to an eye specialist. It was apparent from the notes that 23 were too ill to participate in the study. Fifteen non-respondents were already under the care of an eye specialist (19\%), one person was registered blind, another was registrable, and one was registered partially sighted. Four were visually impaired by WHO criteria (prevalence $4.9 \%$; $95 \%$ confidence interval $1 \cdot 4 \%$ to $12 \cdot 2 \%$ ). There were eight subjects with low vision known to the practice among the respondents $(3 \cdot 9 \% ; 1 \cdot 7 \%$ to $7 \cdot 5 \%)$. These proportions did not differ significantly.

There were four known patients with glaucoma receiving treatment who did not attend (prevalence $4.9 \%$; $95 \%$ confidence interval $1 \cdot 4 \%$ to $12 \cdot 2 \%$ ). The remaining 32 had no comment on eye health or significant medical problem recorded in the practice notes.

PATHOLOGICAL CAUSES OF BLINDNESS, LOW VISION, AND VISUAL IMPAIRMENT

Blindness in one woman was due to aging maculopathy with bilateral disciform degeneration. The second had thrombotic glaucoma in one eye and glaucoma, pseudophakia, and disciform degeneration in the other. Four of the six further cases found with vision less than $6 / 36$ were due to cataract. The fifth was due to ischaemic optic neuropathy and the sixth to optic atrophy.

In cases where more than one disorder was present, such as cataract or mild aging changes at the macula (for example, drusen or minor changes in the retinal pigment epithelium), a clinical decision was made by RPLW in order to determine the main cause of blindness or visual impairment.

Cataract accounted for the majority of cases of low vision and visual impairment (see figure). The prevalence of cataract in the total sample tested, as defined by lens opacity reducing the vision to less than $6 / 18$, was $5.8 \%$ (95\% confidence interval $3.0 \%$ to $9.9 \%$ ). In the $65-74$ age group the prevalence of cataract was $1 \%$ $(0.03 \%$ to $5 \cdot 8 \%)$, increasing to $10.4 \%$ in the group aged 75 and over $(4 \cdot 6 \%$ to $16 \cdot 2 \%)$.

There were 12 aphakic participants $(5.8 \% ; 95 \%$ confidence interval $3.0 \%$ to $9.9 \%$ ), 10 with lens implants and two without.

Aging maculopathy caused reduced vision (less than $6 / 18$ ) in the better eye in three people over 75 , giving a prevalence of $2 \cdot 8 \%$ ( $95 \%$ confidence interval $0.5 \%$ to $8.0 \%$ ) for that age group and an overall prevalence of $1 \cdot 4 \%(0 \cdot 3 \%$ to $4 \cdot 2 \%)$ (figure). The prevalence of

Prevalence of blindness and visual impairment by different definitions and age group

\begin{tabular}{|c|c|c|c|c|c|c|c|c|c|}
\hline \multirow[b]{2}{*}{ Definition } & \multicolumn{3}{|c|}{ Age $65-74$ years } & \multicolumn{3}{|c|}{ Age $\geqslant 75$ years } & \multicolumn{3}{|c|}{ Total } \\
\hline & No & $\begin{array}{c}\text { Prevalence } \\
(\%)\end{array}$ & $\begin{array}{c}95 \% \\
\text { Confidence } \\
\text { interval }\end{array}$ & No & $\begin{array}{c}\text { Prevalence } \\
\text { (\%) }\end{array}$ & $\begin{array}{c}95 \% \\
\text { Confidence } \\
\text { interval }\end{array}$ & No & $\begin{array}{c}\text { Prevalence } \\
\text { (\%) }\end{array}$ & $\begin{array}{c}95 \% \\
\text { Confidence } \\
\text { interval }\end{array}$ \\
\hline \multicolumn{10}{|l|}{ Males and females: } \\
\hline Blind $<3 / 60$ & $0 / 101$ & 0 & 0 & $2 / 106$ & 1.9 & 0.2 to $6 \cdot 6$ & $2 / 207$ & $1 \cdot 0$ & 0.15 to $3 \cdot 4$ \\
\hline Blind $<6 / 36$ & $1 / 101$ & 0.99 & 0.03 to 5.4 & $\begin{array}{c}7 / 106 \\
4 / 80^{\star}\end{array}$ & $\begin{array}{l}6 \cdot 6 \\
5 \cdot 0\end{array}$ & $\begin{array}{l}2.7 \text { to } 13 \cdot 1 \\
1.4 \text { to } 12.3\end{array}$ & $8 / 207$ & 3.9 & $1 \cdot 7$ to $7 \cdot 5$ \\
\hline Low vision $<6 / 18$ & $1 / 101$ & 0.99 & 0.03 to 5.4 & $15 / 106$ & $14 \cdot 2$ & $7 \cdot 5$ to $20 \cdot 8$ & $16 / 207$ & $7 \cdot 7$ & $4 \cdot 5$ to $12 \cdot 2$ \\
\hline Visual impairment $<6 / 12$ to $>6 / 60$ & $1 / 101$ & 0.99 & 0.03 to 5.4 & $21 / 106$ & $19 \cdot 8$ & $12 \cdot 2$ to $27 \cdot 4$ & $22 / 207$ & $10 \cdot 6$ & $6 \cdot 4$ to 14.8 \\
\hline \multicolumn{10}{|l|}{ Males: } \\
\hline Blind $<3 / 60$ & $0 / 38$ & 0 & 0 & $0 / 28$ & 0 & 0 & $0 / 66$ & 0 & 0 \\
\hline Blind $<6 / 36$ & $0 / 38$ & 0 & 0 & $\begin{array}{l}1 / 28 \\
1 / 24^{\star}\end{array}$ & $\begin{array}{l}3.57 \\
4 \cdot 17\end{array}$ & $\begin{array}{r}0.09 \text { to } 18.4 \\
0.1 \text { to } 21.1\end{array}$ & $1 / 66$ & $1 \cdot 5$ & $4 \cdot 3$ to $8 \cdot 2$ \\
\hline Low vision $<6 / 18$ & $0 / 38$ & 0 & 0 & $3 / 28$ & $10 \cdot 7$ & $2 \cdot 3$ to $28 \cdot 2$ & $3 / 66$ & $4 \cdot 5$ & 0.95 to 12.7 \\
\hline Visual impairment $<6 / 12$ to $>6 / 60$ & $0 / 38$ & 0 & 0 & $6 / 28$ & $21 \cdot 4$ & 8.3 to 40.9 & $6 / 66$ & $9 \cdot 1$ & 3.4 to 18.7 \\
\hline \multicolumn{10}{|l|}{ Females: } \\
\hline Blind $<3 / 60$ & $0 / 63$ & 0 & 0 & $2 / 78$ & $2 \cdot 6$ & 0.3 to 8.9 & $2 / 141$ & $1 \cdot 4$ & 0.2 to 5.0 \\
\hline Blind $<6 / 36$ & $1 / 63$ & $1 \cdot 59$ & 0.04 to 8.5 & $\begin{array}{l}6 / 78 \\
3 / 56^{\star}\end{array}$ & $\begin{array}{l}7 \cdot 7 \\
5 \cdot 4\end{array}$ & $\begin{array}{l}2.9 \text { to } 16.0 \\
1.1 \text { to } 14.9\end{array}$ & $7 / 141$ & $5 \cdot 0$ & $2 \cdot 0$ to $10 \cdot 0$ \\
\hline Low vision $<6 / 18$ & $1 / 63$ & 1.59 & 0.04 to 8.5 & $12 / 78$ & $15 \cdot 4$ & $8 \cdot 2$ to $25 \cdot 3$ & $13 / 141$ & $9 \cdot 2$ & $5 \cdot 0$ to $15 \cdot 3$ \\
\hline Visual impairment $<6 / 12$ to $>6 / 60$ & $1 / 63$ & 1.59 & 0.04 to 8.5 & $15 / 78$ & $19 \cdot 2$ & $11 \cdot 2$ to $29 \cdot 7$ & $16 / 141$ & $11 \cdot 3$ & $6 \cdot 1$ to $16 \cdot 6$ \\
\hline
\end{tabular}

*Age $75-84$ years. 


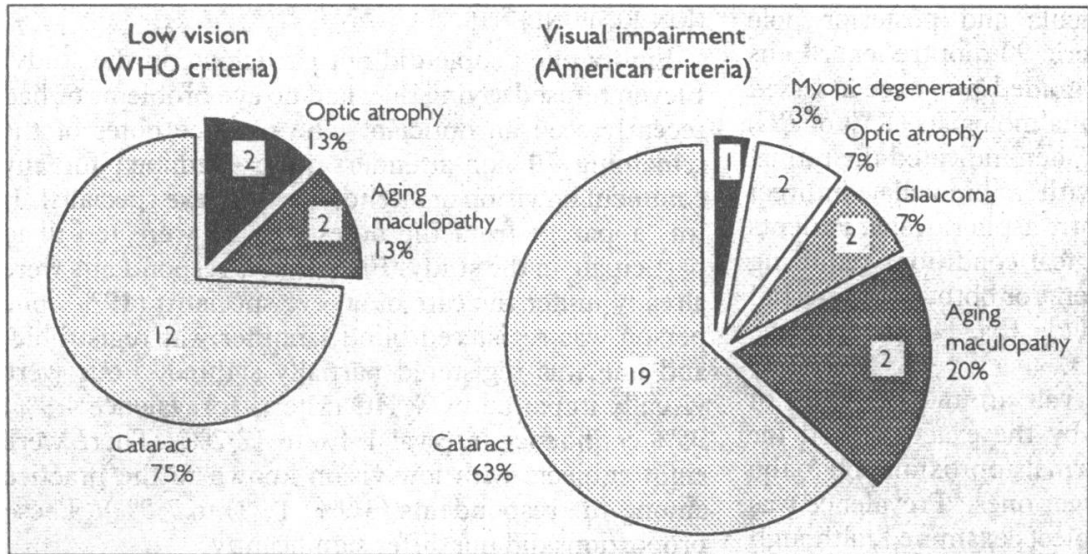

Causes of low vision and visual impairment

clinically obvious predisposing changes at the macula associated with visual loss in at least one eye was higher (25\%).

Three new cases of glaucoma were confirmed in the sample as well as six known cases in people who were already receiving treatment, giving an overall prevalence of $4 \cdot 4 \%$ (95\% confidence interval $2 \cdot 0 \%$ to $8 \cdot 0 \%$ ). All but two of these patients were over 75 years of age. Diabetic retinopathy was found in only two subjects $(1 \% ; 0 \cdot 1 \%$ to $3 \cdot 4 \%)$, both under 75 . There were 14 known diabetics in the sample. Many other minor abnormalities of the eyes and adnexa were found. Only 68 participants (33\%) had an entirely normal examination result.

Thirty three people were referred to the hospital eye service (16\%), and 15 of these had previously been under the care of an eye specialist, but only three had active hospital numbers. Although only three of the 13 referrals for suspected glaucoma could be confirmed as cases (two normal tension cases, one chronic angle closure glaucoma), all but one were followed up for further evaluation. Other referrals were for cataract (12), lid or lacrimal conditions (four), diabetic retinopathy (one, newly diagnosed), branch vein occlusion (one), and blind or partial sight registration (two).

\section{Discussion}

The response rate of $72 \%$ in this survey compared favourably with the Framingham eye study ${ }^{5}(67 \%$ response) but was less than in some other studies. ${ }^{4-10}$ When the Framingham data were compared with ours for the prevalence of any lens opacity reducing vision to less than $6 / 12$ (not including aphakia) the prevalence in London was significantly higher in subjects aged 75 and over (age 65-74: Framingham $0.7 \%$ (95\% confidence interval $0.3 \%$ to $1.5 \%)$, London $2 \%(0.24 \%$ to $7 \cdot 0 \%)$; age $\geq 75$ : Framingham $3 \cdot 8 \%(2 \cdot 1 \%$ to $6 \cdot 2 \%)$, London $16.4 \%$ (9.0\% to $23.0 \%)$; overall: Framingham $1 \cdot 7 \%(1.0 \%$ to $2 \cdot 6 \%)$, London $9 \cdot 2 \%(5 \cdot 6 \%$ to $14 \cdot 0 \%)$ )

The prevalence of aphakia was very similar in the two studies $(4 \cdot 2 \%$ and $5 \cdot 8 \%$ with overlapping confidence intervals). Three per cent of the sample in a Finnish study were aphakic, ${ }^{9}$ but the author commented that in $53 \%$ of the sample with vision reduced to $6 / 18$ or less the reduction was attributable to cataract. This compares with $63 \%$ in our study when using the same criteria (figure). Though the overall prevalences of cataract were similar in these study populations, the prevalence of visually disabling cataract was higher in our sample, especially for people aged 75 and over.

There is evidence that socioeconomic status is a determinant of cataract risk, ${ }^{11}$ professional classes being protected. This might to some extent explain the difference between our sample and that in Framingham.
Visual impairment was common (7/17 cases; 41\%) among the housebound.

Comparisons of prevalence for glaucoma and aging maculopathy were more difficult because of differences in definition. However, there seemed to be no statistically significant differences for glaucoma between this study, the Framingham study, and the Finnish study. ${ }^{9}$

In the Finnish study $10 \%$ of visual loss to a level of $6 / 18$ or less was due to aging maculopathy alone whereas we attributed $20 \%$ of the visual loss by the same criteria. However, numbers were small and the Finnish study did not attribute principal cause. In many cases more than one cause for visual loss was given. Only $1 \%$ of visual loss was attributed to aging maculopathy in the Framingham study.

A notable difference between this study and the Finnish one was the number of participants previously or currently being seen by an eye specialist. Only $25 \%$ of the participants in Turku, Finland, had never seen an ophthalmologist compared with $78 \%$ in this study. Also, $14(11 \%)$ of those who had never seen an ophthalmologist required referral but only one of these referrals was for cataract. A much higher proportion of participants in this study were referred for cataract. Access to an ophthalmologist is clearly easier in Finland and the difference may also be due to greater ophthalmological involvement in routine eye testing in Finland.

The number of ophthalmologists per head of population is much lower in the United Kingdom than the average for European Community countries (1/100 000 compared with 1/20000) (College of Ophthalmologists, personal communication). However, in North East Thames region the ratio is higher than the national average.

Recommendations have been made by several workers over the past few years for screening the elderly for visual disability. ${ }^{12-14}$ This study was started before the implementation of the revised general practitioners' contract, which requires general practitioners to offer yearly health screening (including assessment of vision and hearing) to everyone aged 75 and over on their practice lists. ${ }^{13}$ An assessment has been recommended based on the ability to read newspapers and recognise faces across a room. ${ }^{13}$ Though this may be adequate for near vision, it may miss people who have remediable loss of distance acuity. It is possible to recognise familiar people with remarkably few visual clues.

The Sonksen-Silver $3 \mathrm{~m}$ visual acuity chart is easy to use and well suited to use in primary care. A $3 \mathrm{~m}$ length of cord can be used to ensure that the distance is correct. Evaluation of the red reflex of the eye is also an easy test and quickly performed. It will identify opacities of the ocular media, which most frequently will be due to cataract. The relatively high prevalence of refractive error suggests the need for assessment by an optometrist. However, charges for sight tests, which came into effect before the study, are probably a disincentive for the elderly, especially those who receive only a state pension, to make use of optometrist services.

This study suggests that there is a considerable amount of undetected ocular disease and potentially remediable disability in the community. Only half the visually disabled subjects were known to their doctors to have visual problems before the survey.

We thank Dr S Hunt, Dr D Davidson, and Dr M Cripwell for allowing us to study their patients; Drs Daniel Pauleikhoff and John Wu, who helped in the clinics; Miss Clare Davey, consultant ophthalmologist, for reviewing patients referred to Whittington Hospital and Professors Bird and Jay, whose clinics dealt with referrals to Moorfields Eye Hospital; and the orthoptists and optometrists who participated in the study. We also acknowledge the assistance given by Dr Angela 
Reidy, Norman Dudley, and the staff of the Drovers Day Centre. We particularly thank Mr J Atwill, house governor of Moorfields Eye Hospital, for his support from the outset of the study.

1 Brennan ME, Knox EG. An investigation into the purposes, accuracy, and effective uses of the blind register in England. $\mathrm{Br} \mathcal{F}$ Prev Soc Med 1973:27:154-9.

2 Cullinan TR. The epidemiology of visual disability: studies of visually disabled people in the community. Canterbury: Health Services Research Unit, 1977. people in the
(Report 28.)

3 Office of Population Censuses and Surveys. Surveys of disability in Great Britain. Report 1. The prevalence of disability among adults. London: $\mathrm{HMSO}$ 1988.

4 Gibson JM, Rosenthal AR, Lavery J. A study of the prevalence of eye disease in the elderly in an English community. Trans Ophthalmol Soc UK 1985;104:196-203.

5 Framingham eye study monograph. Surv Ophthalmol 1980;24(suppl):335-610.
6 Pizzarello LD. The dimensions of the problem of eye disease among the elderly. Ophthalmology 1987;94:1191-5.

7 Gardner SB, Winter PD, Gardner MJ. Confidence interval analysis. London: British Medical Journal, 1989.

8 Martinez GS, Camphell AJ, Reinken J, Allan BC. Prevalence of ocular disease in a population study of subjects 65 years old and older. Am $\mathcal{F}$ Ophthalmol 1982;94:181-9.

9 Hakkinen L. Vision in the elderly and its use in the social environment. Scand f Soc Med 1984;suppl 35.

10 Tielsch JM, Sommer A, Witt K, Katz J, Royall RM. Blindness and visual impairment in an American urban population: the Baltimore eye survey. Arch Ophthalmol 1990;108:286-90.

11 Leske MC Chylack LT, Wu S-Y. The lens opacity case-control study. Risk factors for cataract. Arch Ophthalmol 1991;109:244-51.

2. Hitching RA. Visual disability and the elderly. BMF 1989:298:1126-7.

13 Freer CB. Screening the elderly. $B M 7$ 1990;300:1447-8.

14 Sanderson D. Ocular screening for the elderly. The Canadian Nurse 1986 Feb:19-20

(Accepted 18 February 1992
St John's College, Cambridge CB2 1TP

D S Halpern, benefactors' research student

Halton Health Authority, Runcorn WA7 4TH $\mathrm{J}$ Reid, consultant in health medicine

Correspondence to

Mr D S Halpern.

BMF 1992;304:1229-30

\title{
Effect of unexpected demolition announcement on health of residents
}

\author{
D S Halpern, J Reid
}

\begin{abstract}
Objective-To examine the impact of an unexpected announcement of the demolition of a housing estate on the health of the area's residents.

Design-Study of general practitioner consultation rates of the estate's residents after the announcement compared with those of other areas and with those of the previous year.

Setting-General practices in Runcorn, Cheshire.

Patients -17000 patients on lists of the two group practices serving the estate and surrounding area.

Main outcome measure-Relative weekly consultation rates with general practitioners.

Results - The mean adjusted odds ratio for consultation was 1.12 (SD 0.12) when demolition was expected and $0.877(0.05)$ when it was not $(t=5.94$, $p<0.001)$. The difference remained after the adjustment for the fall in the estate's population was removed $(t=3.7, \mathrm{p}<0.01)$.
\end{abstract}

Conclusion-Announcement of the estate's demolition adversely affected residents' health.

\section{Introduction}

On 21 February 1989 the decision to demolish the Southgate housing estate, Runcorn, a total of 1300 dwellings, was announced. The surprise decision dismissed alternative plans for the estate's refurbishment that had been prepared by a local housing association in consultation with the residents. The development corporation sent letters to the estate's 2000 residents informing them of the decision. During the next eight weeks there was vigorous resident activity and protest, culminating in an apparently successful meeting with the under secretary of state (on 14 April 1989). However, within four weeks the original decision to demolish was reconfirmed. Anecdotal experience of distressed residents was apparent to the local public health physician (JR), who was participating in medical rehousing, and we conducted this study to quantify the effect on residents' health.

\section{Subjects and methods}

We studied the records of general practitioner consultations for the first six months of 1989 and, for comparison, 1988 , to determine changes in consultation patterns. We manually checked the old appointment sheets of the two practices that served the estate and the immediately surrounding area. Each consultation was classified according to the patient's home address (Southgate or non-Southgate) to give weekly numbers of consultations. The weekly numbers of consultations by Southgate residents ( $\mathrm{n}$ ) were then expressed as a ratio of consultations by non-Southgate residents $(\mathrm{N})$. The ratio $(\mathbf{n} / \mathrm{N})$ controlled for spurious fluctuations in the absolute numbers of patients seen in any given week. For example, seasonal variations in consultations would cause fluctuations in the absolute number of Southgate and other patients seen, but leave the ratio largely unaffected. Similarly, if one or two of the practices' nine doctors happened to be away this might reduce the absolute numbers of patients seen but not the ratio. (No general practitioner specialised in patients from the Southgate estate.) Hence, the ratio provided an unbiased estimate of the relative rate of Southgate residents' consultations with general practitioners over the period studied - that is, it provided a good measure of estate specific variation.

The ratio would not account for some estate specific, seasonal variation. For example, interactions between the time of year and the consultation rate might occur due to the relative affluence of residents (poorer residents being less able to heat their homes in winter). Similarly, if an estate had an unusually large (or small) number of children or elderly people, and if these groups were differentially affected by variations in rates of illness, this could introduce estate specific variation. This was controlled for by comparing consultations not only with those of other estates in the same week but also with the rate in the same week in the previous year. This gave the formula $\left(\mathrm{n}_{1} / \mathrm{N}_{1}\right) /$ $\left(\mathrm{n}_{2} / \mathrm{N}_{2}\right)$, the odds ratio of Southgate consultations to non-Southgate consultations, 1989 to 1988.

Finally, we corrected for changes in the size of the baseline population. The number of occupied units on the estate in any given week $\left(U_{1}\right)$ was derived from records kept by the officers of the housing association. (The housing association was responsible for the day to day management of the estate.) This allowed the calculation of an adjustment factor $\left(U_{\text {base }} / U_{1}\right)$, where $\mathrm{U}_{\text {base }}$ was the baseline number of units occupied during the past year. Delays in patients registering changes in address were accounted for by offsetting the value of $\mathrm{U}_{1}$ by three weeks. This correction factor was calculated on the basis of information from the practice administrators. This led to a final formula $\left(\left(\mathrm{n}_{1} / \mathrm{N}_{1}\right) /\left(\mathrm{n}_{2} / \mathrm{N}_{2}\right)\right) \times$ $\left(\mathrm{U}_{\text {base }} / \mathrm{U}_{1}\right)$.

We calculated the ratios for each week of the 